\title{
Investigating Recast and Metalinguistic Feedback in Task-based Grammar Instruction
}

\author{
Saeed Rezaei \\ Allameh Tabataba'i University, Iran \\ Email: rezaei63@yahoo.com \\ Ali Derakhshan \\ Allameh Tabataba'i University, Iran \\ Email: aderakhshanh@gmail.com
}

\begin{abstract}
This quasi-experimental study investigated the effect of two types of Corrective Feedback (CF) in task-based grammar instruction (TBGI). After administering a Nelson test (for the intermediate) sixty participants out of one hundred were selected from the intact classes. These sixty participants were randomly assigned to three groups: recast, metalinguistic, and no-feedback group respectively each comprising of twenty participants. After that a test, developed by the researcher inquiring the conditionals and wish statements, was given to the participants in order to assure that the participants did not have a prior knowledge of these target structures. After the treatment was given to each group, the posttest was given in order to measure the effectiveness of the instructional approaches in each group. The results of the one-way ANOVA and the t-test revealed that first of all both CF types were effective in TBGI and secondly between the two CF types metalinguistic feedback was more effective than recast. The results of this study are considered to be useful in methodological issues related to error correction techniques, and teacher educators training pre-service or inservice teachers.
\end{abstract}

Index Terms - corrective feedback (CF), recast, metalinguistic feedback, grammar, task

\section{INTRODUCTION}

Research in first language (L1) and second language (L2) is a dynamic process every now and then undertaking a specific area of the complex system of language. One of the main areas of research in L1 and L2 research which has recently been resurrected is the significance of error treatment/correction and its subsequent effects on language learning. Also, task-based language teaching is an area which has been put on pedestal by Second Language Acquisition (SLA) researchers including Ellis (2003). A lot is being done in these two areas and this is a good reason for the vitality and fertileness of these two lines of research. However, a big question mark on the top of language researchers' heads which is constantly bewildering both our language researchers and practitioners is the way error correction occurs through various $\mathrm{CF}$ techniques especially in grammar instruction. Questions like how to treat errors, when to treat errors, which type of errors to treat and the like are the main questions directing this line of research.

Researchers in this area have investigated $\mathrm{CF}$ and its effect on different aspects of language including grammar, pronunciation, and writing accuracy (e.g. Bitchener and Knoch, 2008; Ellis, Loewen, \& Erlam, 2006; Gass, Mackey, \& Ross-Feldman, 2005). Studies on CF and grammar instruction approaches have yielded different results, some confirming the previous research and some others casting doubt on what the predecessors have tackled. These differing results leave us in a quandary. Shall I correct? Does my correction affect the learners' feelings? Should I terminate the flow of speech or...? All the above-mentioned questions and so many others lead us to make a final decision and put an end to all our irresolution and uncertainty. This was the primary reason for conducting the present study.

\section{BACKGROUND}

One of the main concerns of researchers in the area of error correction and CF is the legitimate question of whether errors should be corrected or not. Hendrickson (1978) argues that (a) errors should be corrected; (b) global errors, rather than local errors, should be corrected; and (c) errors should be corrected with consistency and systematicity. However, opponents of error correction such as Truscott (1999) argue that it causes "embarrassment, anger, inhibition, and feelings of inferiority" (p.441). On the other hand, Krashen (1981) stresses his 'no-interface' position with no error correction. Nevertheless, currently SLA researchers strongly believe in error correction and CF (e.g. Ellis, Loewen, Erlam, 2006; Long, 1996; Saxton, 1997).

Research in the area of interactional feedback and how conversation and feedback might lead to language development is partly informed by direct contrast hypothesis which is defined within the context of child language acquisition as follows:

When the child produces an utterance containing an erroneous form, which is responded to immediately with an utterance containing the correct adult alternative to the erroneous form (i.e., when negative evidence is supplied), the 
child may perceive the adult form as being in contrast with the equivalent child form. Cognizance of a relevant contrast can then form the basis for perceiving the adult form as a correct alternative to the child form (Saxton, 1997; p.155 emphasis in original).

According to this hypothesis, when the child recognizes the contrast between the adult construction and his/her construction, the first step in modifying its language system to the language norms occurs.

On the other hand, as part of his own experience as a learner of Portuguese Schmidt $(1990,2001)$ postulates that input does not become intake for language learning unless it is noticed, i.e., consciously registered. As part of his strong version of the noticing hypothesis, he further proposed that nothing is learned unless it has been noticed. In a more conservative weak version, it is said that noticing does not itself result in acquisition, but it paves the way for acquisition to occur. However, connectionists believe that the likelihood of acquisition is best achieved by the frequency with which something is available for processing, not the noticing alone. Noticing hypothesis is related to CF studies in that attention, noticing, and awareness, are crucial in perceiving different types of feedback and enhancing their benefits for language learners.

In addition, Long's (1996) interaction hypothesis proposes that feedback obtained during conversational interaction promotes interlanguage (IL) development because interaction 'connects input, internal learner capacities, particularly selective attention, and output in productive ways' (Long, 1996, pp. 451-452). As Han (2002) argues, much of the L2 research on recast is motivated by Long's Interaction Hypothesis. This hypothesis was proposed by Long in two versions, first in 1980s and the updated version in 1996. This hypothesis strongly insists that language acquisition requires or greatly benefits from interaction, communication, and especially negotiation of meaning which are salient in CF.

\section{DIFFERENT TYPES OF CORRECTIVE FEEDBACK $(\mathrm{CF})$}

Lyster and Ranta (1997) identified five corrective strategies other than recasts (i.e., explicit correction, clarification requests, metalinguistic information, elicitation, and repetition), whereas Panova and Lyster (2002) added one more, i.e., translation. Here only recast and metalinguistic feedback are explained.

\section{A. Recast}

As a CF technique, recasts were initially used by L1 acquisition researchers (e.g., Bohannon \& Stanowicz, 1988) who observed that adults or caregivers tended to repair their children's ill-formed utterances by recasting morphosyntactic or semantic errors therein. In L1 studies, Nelson, Carskaddon, and Bonvillian (1973) appear to have been the first to use the term recast to refer to responses by adults to children's utterances(cited in Nicholas, Lightbown, \& Spada, 2001; p.724).

Despite the various definitions proposed for corrective recasts in the related literature, there seems to be a set of definite agreed-upon characteristics inherent in corrective recasts as recapitulated here: a recast (is)

- a corrective move which comes after an erroneous utterance,

- a reformulation of the ill-formed utterance,

- an expansion of the ill-formed utterance, and

- maintains its central meaning

There are some advantages and limitations discussed in the literature. Several theoretical reasons emphasize the importance and effectiveness of recasts in SLA studies (Long, 2006; Saxton, 2005). First of all, recasts pop up in meaningful communicative activities where interlocutors share a "joint attentional focus" (Long, 2006; p. 114). Second, the reactive nature of recasts bring a specific feature into focus which brings with it attention and motivation on the part of the learners. Third, the content of recasts is considered to be comprehended by the learners and hence provide the learners with additional resources available, which in turn facilitates learners' form-function mapping (Doughty, 2001). Fourth, due to the reactive nature of recasts they do not impede the flow of communication and are hence considered to be more effective and helpful than explicit CFs.

However, there are some criticisms leveled against recast. The first limitation of recast is related to its being noticeable or not and their ambiguous nature. Although recasts are upheld by some researchers as an effective CF technique, others (e.g., Lyster, 1998a; Panova \& Lyster, 2002) believe that recasts usually pass unnoticed by the learners and hence are not facilitative for IL development. Another issue raised against recasts relevant to the previous one is that duo to their ambiguous nature they might be perceived as synonymous in function to mere repetition for language learners (e.g., Long, 2006; Lyster \& Ranta, 1997; Morris \& Tarone, 2003; Nicholas et al, 2001). The third limitation of recasts is related to its repairing function, i.e. according to Loewen and Philp (2006) recasts do not elicit repair and learners are simply provided with the correct form without being pushed to modify their IL. Furthermore, as the forth limitation of recasts we can refer to its various effectiveness based on the targeted form under study. In other words, Loewen and Philp (2006) believe that based on previous research (e.g., Ellis \& Sheen, 2006; Long, 1996) recasts may be differentially effective depending on the targeted form under study.

\section{B. Metalinguistic Feedback}

Much like explicit error correction, metalinguistic feedback- because it diverts the focus of conversation towards rules or features of the target language- falls at the explicit end of the CF spectrum. Lyster and Ranta (1997) categorize metalinguistic 
feedback as "comments, information, or questions related to the well-formedness of the student's utterance, without explicitly providing the correct form". Despite its name, however, Lyster and Ranta (1997) explain that metalinguistic feedback need not contain metalanguage. That is to say, though it is indeed possible, even likely, for metalinguistic feedback to contain metalanguage, the inclusion of metalanguage is not the defining characteristic of metalinguistic feedback. Instead, the defining characteristic of metalinguistic feedback is its encoding of evaluations or commentary regarding the non-target-like nature of the learner's utterance. By encoding direct reference to the existence of an error or to the nature of the error, metalinguistic feedback supplies the language learner with negative evidence regarding the target form. Lyster and Ranta (1997) go on to divide metalinguistic feedback into three different subcategories:

1. Metalinguistic comments,

2. Metalinguistic information, and

3. Metalinguistic questions

Metalinguistic comments, the most minimally informative of the three, simply indicate the occurrence of an error. Such metalinguistic feedback may include a general statement that an error has occurred (e.g. Can you find your error) or may directly pinpoint the error (e.g. Not X). The next subcategory of metalinguistic feedback- metalinguistic information- goes beyond simply indicating the occurrence or location of the error and "generally provides some metalanguage that refers to the nature of the error" (Lyster \& Ranta, 1997, p. 47). Thus, metalinguistic information can provide the learners with a range of hints concerning the possible reformulation of the non-target-like form. This can range from the most general information which labels the type of error made to information regarding a more target-like alternative, particularly when there are more than two potential options. The third subcategory of metalinguistic feedback identified by Lyster and Ranta (1997) metalinguistic questions- "point to the nature of the error but attempt to elicit the information from the student". Unlike metalinguistic information which uses metalanguage to label the nature of the error, metalinguistic questions call upon the learner to reconsider their assumptions regarding the target language form (e.g. did you use dative?).

\section{MAJOR STUDIES ON ERROR CORRECTION IN L1 \& L2}

As abovementioned, CF was initially an area of research in L1 studies (e.g. Brown and Hanlon, 1970). In fact, studies on CF in L2 development has been inspired by research results in L1 acquisition (Farrar, 1990, 1992).

A quick review of literature indicates that the last decade has witnessed so many studies done in the area of $\mathrm{CF}$ and L2 development. Early studies on CF and error studies in SLA can be traced in 1970s (e.g., Hendrickson, 1978).

However, the results regarding the effectiveness of recasts are contradictory. Nicholas et al (2001) believe that the contradictory interpretations of recasts can be attributed to the different contexts, in which recasts are implemented, i.e. classroom vs. laboratory settings. Nicholas et al (2001) further argue that recasts seem to be more effective in a laboratory context than in a classroom context, probably due to the fact that target item and type of feedback tend to be highly controlled and attended to in a laboratory setting, so that learners are likely to recognize the intention of the feedback and differentiate it from simple repetitions. On the other hand, studies in a classroom setting generally suggest the ineffectiveness of recasts as CF (e.g., Lyster, 1998; Lyster \& Ranta, 1997; Morris \& Tarone, 2003; Panova \& Lyster, 2002). One potential source of problem with such results was that many of the classroom studies based their claims on uptake, defined as learners' immediate use of recasts, or lack thereof. Conversely, studies conducted in a tightly controlled laboratory setting, using a pretest-posttest design, generally support the benefits of recasts for learning (e.g., Mackey \& Philp, 1998). In brief, these mixed findings about the utility of recasts in SLA seem to have partly resulted from measures of development and the contexts in which studies were conducted (classroom vs. laboratory and/or teacher-fronted interaction vs. dyadic interaction).

In a quasi-experimental study with a pretest-posttest control group design, Ammar and Spada (2006) investigated the effects of recasts and prompts on L2 learners' written and oral ability across different proficiency levels. The results of this study indicated that prompts were more effective than recasts and that the effectiveness of recasts was sensitive to the learners' proficiency level. In particular, high-proficiency learners benefited equally from both prompts and recasts, whereas low-proficiency learners benefited significantly more from prompts than recasts. Also, McDonough and Mackey (2006), in pre-test post-test design investigated the impact of recasts and different types of responses for the development of question formation among Thai English as a foreign language. The results revealed that both recasts and learners' primed production of the syntactic structures targeted in the recasts are predictive of subsequent development. In addition, Ellis, Loewen, and Erlam (2006) in an experimental study investigated the effects of explicit and implicit CF on the acquisition of past test '-ed' among low-intermediate learners. The implicit feedback in this study was recast and the explicit feedback was metalinguistic feedback. The results of this study indicated that explicit feedback containing metalinguistic information is more effective than implicit feedback containing recasts.

Ammar (2008) in a quasi-experimental study compared the differential effect of recast and prompts for third person possessive determiners among Francophone learners. The participants were given CF meanwhile they were doing some communicative activities. The results based on picture description tasks and computerized fill-in-the-blanks tasks indicated that prompts were more effective than recasts in the learners' development of third person possessive determiners.

Dabaghi (2008) also investigated the effect of explicit and implicit correction in grammatical errors made by language learners. Simultaneously he investigated the effects of explicit and implicit error corrections in morphological 
and syntactic errors and the correction of developmental early and late features. The results of his study indicated that explicit error correction techniques were significantly more effective than implicit CF techniques.

Running in the same line, Nassaji (2009) investigated two types of interactional feedback, i.e. recasts vs. elicitations and their subsequent effects in grammatical features popping up in incidental dyadic interactions. This study investigated both immediate and delayed effects of CFs. The results of his study revealed that recasts were more effective than elicitations in immediate effects. Also the results of this study indicated that in both CF types, the more explicit form was more effective than its implicit form. Therefore the degree of explicitness was reported to be very crucial in the effectiveness of these two types of CF.

Lyster \& Izquierdo (2009) also in a recent study investigated the effect of two different types of CFs in the acquisition of grammatical gender among adult French learners. The focus of their study was exclusively directed toward the differential effects of recasts vs. prompts in dyadic interactions. The results found both types of feedbacks effective.

To summarize, the findings of the studies presented in this section suggest that the results are contradictory in the area of CF. All in all; more research is required in this area in order to establish an agreed-upon conception about the ambiguity of recasts in their effectiveness for L2 development and the possible superiority of any of these CF techniques in SLA.

\section{RESEARCH QUESTIONS}

The current study seeks the following research questions:

1. Is Task-based grammar instruction more effective with feedback (i.e. recast vs. metalinguistic feedback) than without any feedback?

2. Which type of feedback is more effective in task-based grammar instruction, recast or metalinguistic feedback?

\section{METHOD}

\section{A. Participants}

The participants of the current research were from three intact classes at the Iran Language Institute (ILI) in Tehran. Each of these three classes consisted of twenty to thirty male students and their age ranged from 15 to 25 .

Of the whole participants, 7 were excluded due to their inadequate English proficiency for the purpose of this study and 5 others were excluded since they missed some of the treatment sessions. Finally 60 participants remained, each group comprising of 20 male participants and hence fulfilling the purpose of balanced design in research.

\section{B. Sampling}

The researcher employed accidental or convenience sampling in intact classes. Accidental, haphazard, or convenience sampling is a non-probability sampling technique that simply uses conveniently available subjects (Dörnyei, 2007). However, the participants were randomly assigned to three groups, i.e. group assignment occurred randomly.

\section{Instrumentation}

\section{Proficiency Test}

Nelson English language test 200 A, adapted from Fowler and Coe (1976) devised for intermediate level was used as a proficiency test in order to assure the homogeneity of the groups. The Nelson test of proficiency for the intermediate comprised of fifty items. Of these fifty items, fourteen items were cloze test and thirty six others were structure tests. This test inquired the following grammatical features:

- Comparative adjective

- Some, any, no, much, many...

- So and too

- Reflexive pronoun

- Tag questions

- Nowhere, everywhere, somewhere

- ...

The descriptive results of this proficiency this is shown table 1 below.

TABLE 1 .

DESCRIPTIVE STATISTICS: PROFICIENCY TEST

\begin{tabular}{|c|c|c|c|c|c|}
\hline & N & Minimum & Maximum & Mean & Std. Deviation \\
\hline G1 & 20 & 28 & 46 & 37 & 5.92 \\
G2 & 20 & 26 & 46 & 37.1 & 6.42 \\
G3 & 20 & 30 & 46 & 37.2 & 5.03 \\
Valid N (list wise) & 20 & & & & \\
\hline
\end{tabular}




\section{Pretest and Posttest}

This test comprised of items testing the conditionals and wish statements and was administered as the pretest and posttest in a counter-balanced design, i.e. a design in which half of the individuals take one form of the test first and the other half take the other form first (Mousavi, 2009). The purpose of this test for pre-test was to make certain that the learners did not have prior knowledge of conditionals and wish statements. It is important to note that since there was no valid and reliable ready-made test in the market fulfilling the purpose of this research, this pre-test was developed by the researcher. At first, a test of 100 items was developed and after pilot testing it, i.e. trying out the newly written test before final administration, items analysis was done on this test. Through item analysis, poor items were either discarded or modified and finally 50 items remained. The reliability index for this test was 0.78 . It is needed to add here that the items were made based on different types of conditional structures and wish sentences, i.e. it was developed based on a pool of these target structures. The same test was used as the posttest to measure the effectiveness of the instructional approaches.

Target Grammar Structures

The researcher selected conditionals and wish statements for this study due to their frequency and communicative value. In addition, they seem to be more easily applicable in task-based language teaching. Moreover, as far as the researcher is concerned, no study has investigated these grammar structures in CF and task-based language teaching. Moreover; the learners seemed to have problems with these grammatical structures.

Tasks

In this study, focused task was employed which is "an activity which has all the characteristics of a task but has been designed to induce learners' attention to some specific linguistic form when processing either input or output' (Ellis, 2003 ; p. 342). First the participants in $G_{1}, G_{2}$, and $G_{3}$ were taught the grammatical features and then in order to establish what they have been taught, they were given the tasks to complete in pairs. In order to familiarize them with the tasks, the researcher provided the students with a model prior to completing the tasks.

\section{PROCEDURE}

This quasi-experimental study was conducted at the Iran Language Institute in Tehran. Three intact English classes from this institute which were taught by the researcher were selected for the purpose of this quasi-experimental study. These three classes met twice a week, each session 105 minutes of language instruction. The selection of the conditionals and wish clauses was made on the basis of a number of reasons including:

Students had many problems with these two target structures.

These two target structures are very salient and useful.

Focused tasks addressing the use of these two target structures are more easily made.

Based on the design of this study, three equal classes whose homogeneity was established through Nelson English Language Test were randomly assigned to two experimental and one comparison group. These three groups were:

$G_{1}$ ) Task-based grammar instruction with recasts

$G_{2}$ ) Task-based grammar instruction with metalinguistic feedback

$G_{3}$ ) Task-based grammar instruction without feedback on form

In all the experimental groups in this study, the researcher taught the target grammatical features, i.e. conditionals and wish statements through focused tasks following Willis's framework (1996) as shown in table 2.

TABLE 2.

A FRAMEWORK OF TASK-BASED LANGUAGE TEACHING ADAPTED FROM WILLIS, 1996A; P.58

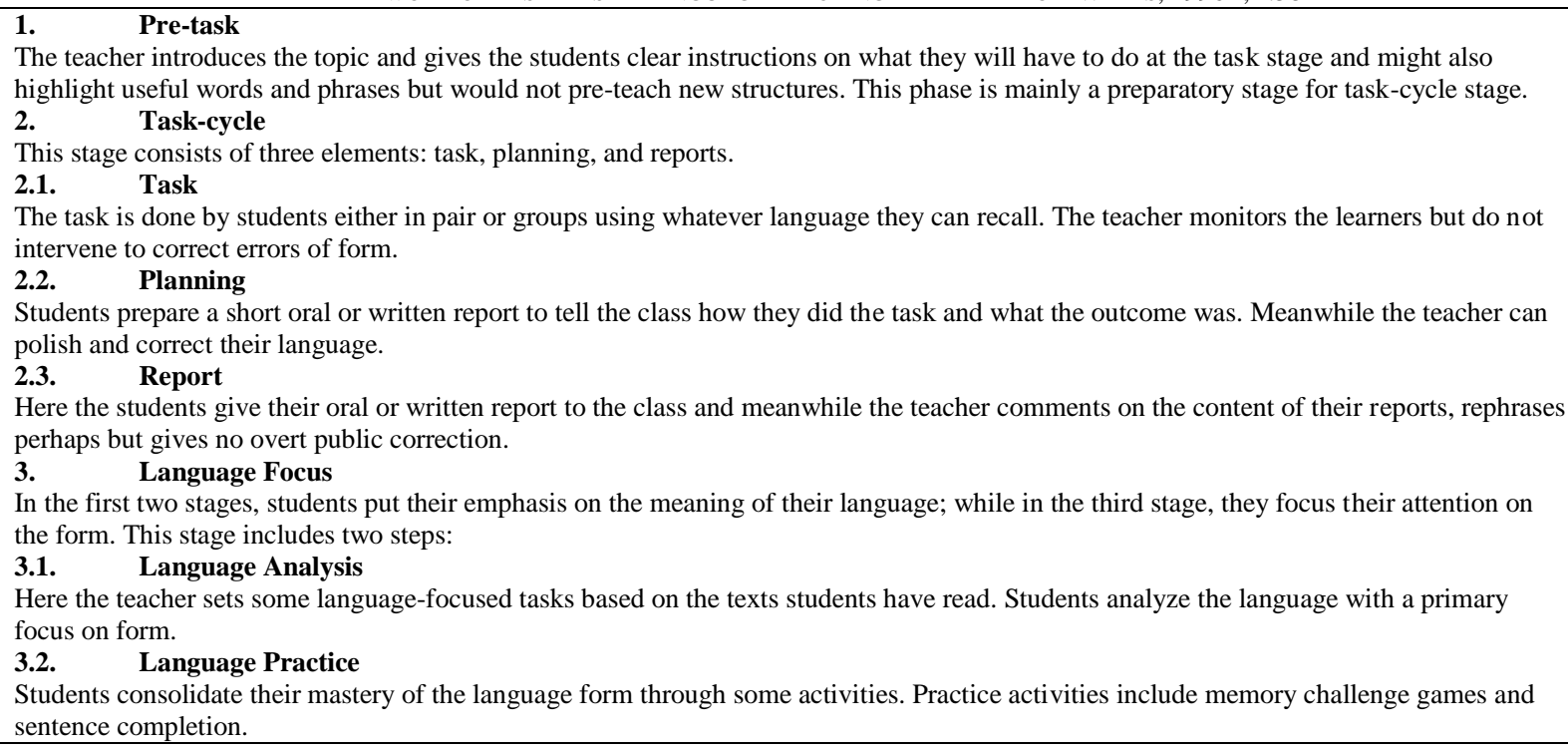


The only difference between the experimental groups in this study was that the researcher who was also the instructor of all the groups adopted different CFs to the learners' errors. In $G_{1}$ the researcher used recast; in $G_{2}$ the researcher used metalinguistic explanation, and finally in $\mathrm{G}_{3}$ the researcher focused only on meaning. Let it be noted here that $\mathrm{CFs}$ were given wherever erroneous utterances were made by the learners. It should also be added here that the feedbacks were provided both to the whole class or individual students.

\section{DATA ANALYSIS \& RESUlTS}

Data gathered through the posttest administered at the end of the study were used to answer the research questions in the current study. In order to answer the research questions, the following statistical procedures were conducted. In response to the first research question, an ANOVA was run comparing the performance of the participants in the three groups including recast, metalinguistic and no-feedback group. This question centered on the effect of CF in task-based grammar instruction. The mean of G1, G2, and G3 are displayed in the figure 1 below.

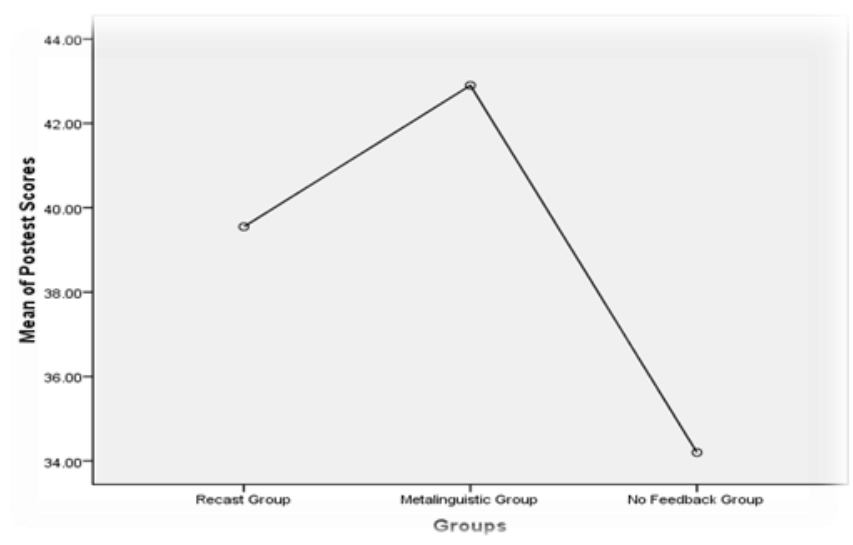

Figure 1. Means of G1, G2, and G3

As the figure indicates, the mean of metalinguistic group is higher than the other two. Table 3 indicates the results of the one-way ANOVA for the first research question in the current study.

TABLE 3.

ONE-WAY ANOVA FOR Q1

\begin{tabular}{|c|c|c|c|c|c|}
\hline Posttest Scores & Sum of Squares & df & Mean Square & F & Sig. \\
\hline Between Groups & 770.23 & 2 & 385.11 & 17.04 & .000 \\
Within Groups & 1287.95 & 57 & 22.59 & & \\
Total & 2058.18 & 59 & & & \\
\hline
\end{tabular}

As clearly indicated in table $1, \mathrm{CF}$ is effective in comparison to no-feedback in task-based grammar instruction of conditionals and wish statements. This result confirms previous studies (e.g., Lyster \& Izquierdo, 2009; Nassaji, 2009; Ammar) regarding the effectiveness of corrective feedback. In other words, CF can potentially weed out the erroneous structures from the learners' utterances and hence approximate the learners' production to the native-like accurate language productions. Lack of CF might lead to the fossilizations of the errors.

The second research question intended to unravel any possible differential effect of different CFs in task-based grammar instruction. In other words, the sole purpose of this research question was to answer the dubious position currently held by the researchers concerning the effect of different types of CF. The descriptive statistics for $G_{1}$ and $G_{2}$ are presented in the table 4 below.

TABLE 4.

DESCRIPTIVE STATISTICS FOR G1 AND G2

\begin{tabular}{|lc|c|c|c|c|}
\hline \multicolumn{2}{c}{ Groups } & N & Mean & Std. Deviation & Std. Error Mean \\
\hline \multirow{2}{*}{ Posttest Scores } & Recast Group & 20 & 39.55 & 5.90 & 1.32 \\
& Metalinguistic Group & 20 & 42.90 & 3.47 & .77 \\
\hline
\end{tabular}

In order to answer the second research question a t-test was run. The results of this t-test are presented in the table 5 below. 
TABLE 5.

INDEPENDENT T-TEST FOR G1 AND G2 PERFORMANCE ON THE POSTTEST (Q2)

\begin{tabular}{|c|c|c|c|c|c|c|c|c|}
\hline & & \multicolumn{2}{|c|}{$\begin{array}{c}\text { Levene's Test for } \\
\text { Equality of Variances }\end{array}$} & \multicolumn{5}{|c|}{ t-test for Equality of Means } \\
\hline & & $\mathrm{F}$ & Sig. & $\mathrm{t}$ & df & Sig. (2-tailed) & $\begin{array}{c}\text { Mean } \\
\text { Difference }\end{array}$ & $\begin{array}{l}\text { Std. Error } \\
\text { Difference }\end{array}$ \\
\hline \multirow[t]{2}{*}{ Post-test } & Equal variances assumed & 2.30 & .137 & -2.18 & 38 & .035 & -3.35 & 1.53 \\
\hline & Equal variances not assumed & & & -2.18 & 30.75 & .037 & -3.35 & 1.53 \\
\hline
\end{tabular}

As the results of t-test reveals in table 3, metalinguistic feedback was more effective than recast in task-based instruction of conditionals and wish statements. We can conclude that metalinguistic feedback is significantly more advantageous over recast as a CF in task-based grammar instruction. This result supports previous research investigating the differential effects of explicit feedback (i.e. metalinguistic feedback) and implicit feedback (i.e. recast) including Dabaghi (2008), Ellis, Loewen, \& Erlam (2006).

\section{DisCUSSION AND RESUlTS}

The results of this and other studies cited in line with the current study extends empirical support for the effectiveness of CF and ergo corroborates the fact that CF can do away with erroneous grammatical patterns inherent in the learners' IL. In other words, in response to the question whether to correct or not we can say that leaving the errors unnoticed might result in the fossilization of these erroneous structures. Hence, the researcher stands against too much error negligence and subsequently concludes that errors should be corrected judiciously either on the spot as in this study or with delay.

Moreover, as shown in the second research question the researcher concluded that metalinguistic feedback was more effective than recasts. The reason for such a result might be partially or wholly due to the explicit nature of metalinguistic feedback. In other words, between the two camps in CF studies where either implicit or explicit feedback is favored, the current researcher takes side with more explicit type of error correction. Such a claim can be especially considered in settings like Iran where learners are after explicit rather than implicit CF. In other words, research has revealed that implicit CFs are usually left unnoticed (e.g. recasts) and hence their corrective effect are less successful when compared with more explicit types of feedbacks. In addition, usually in implicit types of CF such as recast usually the teachers' intent and the learners' interpretation do not match, i.e. the learners usually do not recognize the corrective nature of recasts and might consider recasts as mere teachers' repetition of their utterances. However, the researcher does not claim that implicit types of feedbacks are not effective at all, but they might be less effective in comparison to more explicit types of feedback.

\section{PEDAGOGICAL IMPLiCATIONS}

Acknowledging that one has to be very cautious in drawing implications from a single study and the limitations exerted upon this study, there are pedagogical implications which bring forth fruitful results for language teaching regarding different issues in ELT including, language teaching methodology, teacher training courses for pre-service or in-service teachers.

Novice language teachers have mostly a blur image of new CF techniques and what they practice is based on what they are prescribed to practice in classes by either the institutes or organizations. Keeping them abreast of current theoretical and practical issues related to error correction can be illuminating for language teachers and language educational systems. However, teachers should be alert not to direct the class to over-error-corrections. In such situations, classes might lead to a haphazard amalgamation of the excess use of error correction and hence the main purpose of language learning, i.e. communication, might go to the periphery. Hence, sophisticated use of CF techniques is recommended in language classes.

The results of this study can also be illuminating for teacher training courses. Teacher trainers inculcate certain types of language teaching ideologies and perceptions to their trainees. With regard to the following issues, teacher trainers should be alert to instruct appropriate practices:

a. Error correction techniques and CF types

b. When to correct errors

c. How to correct errors

d. Which types of errors to correct

In brief, teacher trainers should be aware of current theories and ideas about language teaching, so that they will not communicate wrong or outdated teaching techniques to their trainees. The results of this study and the effectiveness of $\mathrm{CF}$ techniques can enlighten the teacher trainers about the effectiveness of such feedback types. Consequently, some space should be allocated to error correction techniques in such teacher training courses for in-service or pre-service teachers. 


\section{LIMITATIONS AND DELIMITATIONS}

The participants in this study were from intact classes at the ILI where convenience sampling was adopted. Hence, the generalizability of this study to larger populations should be considered carefully. The researcher did not consider uptake as a way to evaluate the effectiveness of corrective feedback due to logistical issues like time and facilities (e.g. audio or video recording) for measuring the number of uptakes. Also the level of the language learners was limited to the intermediate level and the grammatical features to conditionals and wish statements.

\section{DIRECTIONS FOR FURTHER RESEARCH}

Based on the current study and what the researchers have already covered for the review section of this study, the researchers offer the following lines of research for the expansion and development of what has already been covered or is currently being done.

A new line of research currently investigated by SLA researchers is the effect of different types of written CFs. Interested researchers can delve into this area for more informative results concerning the effect of CFs in writing or even interlanguage pragmatics among adult or young adults. As researchers contend (e.g. Han, 2002) some linguistic features might be less effective to recasts than other types of feedbacks. Hence, further studies investigating other grammatical structures are required to add credence to the findings obtained in this study and the previous ones and cast away all the doubts regarding the potential effect of different types of CFs for different target structures. Into the bargain, as Ellis \& Sheen (2006) offer, interested researchers can investigate the facilitative impact of learner factors and CFs. Such learner factors include developmental readiness, gender, language aptitude, personality factors, motivation, and teachers' and learners' beliefs and cognition toward correction. Another area for research is $\mathrm{CF}$ in CALL settings (e.g. Sauro, 2009).

\section{REFERENCES}

[1] Ammar, A. (2008). Prompts and recasts: Differential effects on second language morphosyntax. Language Teaching Research $12(2), 183-210$.

[2] Ammar, A., \& Spada, N. (2006). One size fits all? Recasts, prompts and L2 learning. Studies in Second Language Acquisition 28, 543-574.

[3] Bitchener, J., \& Knoch, U. (2008). The value of written corrective feedback for migrant and international students. Language Teaching Research 12 (3), 409-431.

[4] Bohannon, J. N., \& Stanowicz, L. (1988). The issue of negative evidence: Adult responses to children's language errors. Developmental Psychology 24, 684-689.

[5] Brown, R., \& Hanlon, C. (1970). Derivational complexity and order of acquisition in child speech. In: Hayes, J.R. (Ed.), Cognition and the development of language. New York, Wiley. 11-53.

[6] Dabaghi, A. (2008). A comparison of the effects of implicit and explicit corrective feedback on learners' performance in tailormade tests. Journal of Applied Sciences 8 (1), 1-13.

[7] Dörnyei, Z. (2007). Research methods in applied linguistics. Oxford University Press, Oxford.

[8] Doughty, C. (2001). The cognitive underpinnings of focus on form. In: Robinson, P. (Ed.), Cognition and second language instruction. Cambridge, Cambridge University Press.

[9] Ellis, R. (2003). Task-based language learning and teaching. Oxford, Oxford University Press.

[10] Ellis, R., Loewen, S., \& Erlam, R. (2006). Implicit and explicit corrective feedback and the acquisition of L2 grammar. Studies in Second Language Acquisition, 28, 339-368.

[11] Ellis, R., \& Sheen, Y. (2006). Reexamining the role of recasts in second language acquisition. Studies in Second Language Acquisition 28, 575-600.

[12] Farrar, M. J. (1990). Discourse and the acquisition of grammatical morphemes. Journal of Child Language 77, 607-624.

[13] Farrar, M. J. (1992). Negative evidence and grammatical morpheme acquisition. Developmental Psychology, $28,90-98$.

[14] Fowler, W.S., and Coe, N. (1976). Nelson English language tests. Thomas Nelson Ltd.

[15] Gass, S.M., Mackey, A., Ross-Feldman, L. (2005). Task-based interaction in classroom and laboratory settings. Language Learning 55(4), 575-611.

[16] Han, Z-H. (2002). Rethinking of corrective feedback in communicative language teaching. RELC Journal 33, 1-33.

[17] Hendrickson, J. (1978). Error correction in foreign language teaching: Recent theory, research, and practice. Modern Language Journal 62, 387-398.

[18] Krashen, S. (1981). Principles and practice in second language acquisition. Pergamon Press, Oxford.

[19] Loewen, S., \& Philp, J. (2006). Recasts in the adult English L2 classroom: Characteristics, explicitness, and effectiveness. Modern Language Journal 90, 536-556.

[20] Long, M. H. (1996). The role of the linguistic environment in second language acquisition. In: Ritchie, W.C., \& Bhatia, T. K. (Eds.), Handbook of second language acquisition Academic Press, San Diego.413-468.

[21] Long, M. (2006). Problems in SLA. Lawrence Erlbaum Associates, Mahwah, NJ.

[22] Lyster, R. (1998). Recasts, repetition, and ambiguity in L2 classroom discourse. Studies in Second Language Acquisition 20, $51-$ 81.

[23] Lyster, R., \& Izquierdo, J. (2009). Prompts versus recasts in dyadic interaction. Language Learning 59 (2).

[24] Lyster, R., \& Ranta, L. (1997). Corrective feedback and learner uptake: Negotiation form in communicative classrooms. Studies in Second Language Acquisition 19, 37-66. 
[25] Mackey, A., \& Philp, J. (1998). Conversational interaction and second language development: Recast responses, and red herring? Modern Language Journal 82, 338-356.

[26] McDonough, K., \& Mackey, A., (2006). Responses to recasts: Repetition, primed production, and linguistic development. Language Learning 56, 693-720.

[27] Morris, F., \& Tarone, E. (2003). Impact of classroom dynamics on the effectiveness of recasts in second language acquisition. Language Learning 53, 325-368.

[28] Mousavi, S.A., (2009). An encyclopedic dictionary of language testing. (4 $4^{\text {th }}$ ed.). Rahnama Press, Tehran.

[29] Nassaji, H., (2009). Effects of Recasts and Elicitations in Dyadic Interaction and the Role of Feedback Explicitness. Language Learning 59(2).

[30] Nicholas, H., Lightbown, P. M., \& Spada, N., (2001). Recasts as feedback to language learners. Language Learning, 51, 719758.

[31] Panova, I., \& Lyster, R., (2002). Patterns of corrective feedback and uptake in an adult ESL classroom. TESOL Quarterly 36, 573-595.

[32] Saxton, M., (1997). The contrast theory of negative input. Journal of Child Language 24,139-161.

[33] Saxton, M., (2005). 'Recast' in a new light: Insights for practice from typical language studies. Child Language Teaching and Therapy, 21, 23-38.

[34] Schmidt, R., (1990). The role of consciousness in second language learning. Applied Linguistics 11, 129-158.

[35] Schmidt, R., (2001). Attention. In: Robinson, P. (Ed.), Cognition and Second Language Acquisition. Cambridge University Press, Cambridge. 3-32.

[36] Sheen, Y., (2004). Corrective feedback and learner uptake in communicative classrooms across instructional settings. Language Teaching Research 8, 263-300.

[37] Truscott, J., (1999). The case for "the case for grammar correction in L2 writing classes": A response to Ferris. Journal of Second Language Writing 8, 1-122.

[38] Willis, D., \& Willis, J., (1996). A flexible framework for task-based learning. In: Willis, D., Willis, J. (Eds.), Challenges and change in language teaching. Macmillan Heinemann English Language Teaching, Oxford. 52-62.

[39] Sauro, Sh., (2009). Computer-mediated corrective feedback and the development of L2 grammar. Language Learning \& Technology 13 (1), 96-120.

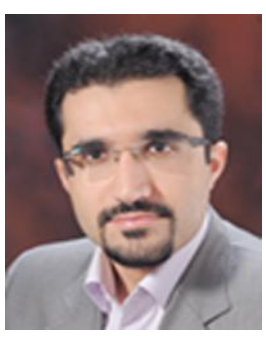

Saeed Rezaei is currently teaching at Sharif University of Technology and Allameh Tabataba'i University in Tehran. He is also a postgraduate student in TEFL at the department of English Language and Literature, Allameh Tabataba'i University (ATU), Tehran, Iran. He received his M.A. in TEFL from ATU and B.A. degree in English Language and Literature from Isfahan University, Isfahan, Iran.

He has presented several papers at ELT conferences held in Iran. He has also published some articles in international journals and authored some books.

His research interests include language education in Iran, SLA, Discourse Studies, L2 Identity, and Materials Development.

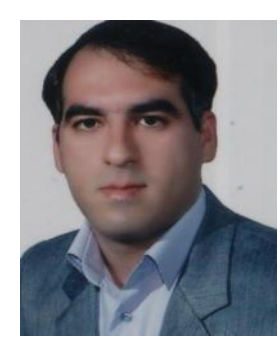

Ali Derakhshan is currently a $\mathrm{PhD}$ candidate majoring in Applied Linguistics at Allameh Tabataba' $\mathrm{i}$ University (ATU), Tehran, Iran. He received his M.A. in TEFL from University of Tehran, Iran. He is a visiting lecturer at Sharif University of Technology and Allameh Tabataba'i University (ATU). He was also opted the best national teacher in two consecutive years. He has coauthored 5 books and published some articles in international journals. His research interests are Language Assessment, Interlanguage Pragmatics Development \& Assessment, Syllabus Design, Teacher Education, Focus on Form/s, and MALL. 